\title{
ONLINE LEARNING DURING LOCKDOWN PERIOD FOR COVID-19 IN INDIA
}

\author{
Dr. Pravat Kumar Jena \\ Assistant Regional Director,IGNOU Regional Centre, Bhubaneswar
}

\begin{abstract}
Covid-19, as a global pandemic, has called for social distancing. It has made people mandatory to sit indoor and sitting idle indoor may lead to mental stress. Hence to keep people engaged and free from mental stress, online learning can play important role. Online learning is the best solution during this pandemic situation. Teachers can use virtual classrooms to teach from home with all necessary tools which makes the online sessions as effective as traditional ones. Pandemics often compel the learners to stay at home for long period of time and obstruct teaching-learning process. This article emphasizes on how online learning is beneficial during times of crises like work absences or pandemics. Therefore, some tools and techniques for online learning which can ensure the continuity of learning are highlighted. Some emerging approaches of Government of India for online learning are presented. Merits and demerits of online learning platform are also discussed. Perceptions of learners and educators on Online Learning system during lockdown are pointed.
\end{abstract}

Keywords: Online Learning, Online Platforms, Perceptions Of Learners \& Educators.

\section{Introduction}

Most Governments around the world have temporarily closed educational institutions to control the spread of the Covid-19 pandemic. With an increasing number of states, provinces and even whole countries closing institutions of learning and over $91 \%$ of the world's students population are not attending schools/colleges (UNESCO). Several other countries have implemented localized closures impacting millions of additional learners. UNESCO is supporting countries in their efforts to slower the immediate impact of school closures particularly for more vulnerable and disadvantaged communities and trying to facilitate the continuity of education for all through remote learning. The World Bank is also actively working with ministries of education in several countries in support of their efforts to utilize educational technologies to provide remote learning opportunities to students while the educational institutions are closed due to Covid-19 pandemic. "The corona virus pandemic has led to an unprecedented rise in present time," said Global Partnership to End Violence Executive Director Dr. Howard Taylor. "School closures and strict containment measures mean more and more families are relying on technology and digital solutions to keep children learning, entertained and connected to the outside world, but not all children have the necessary knowledge, skills and resources to keep themselves safe online" (UNICEF). In this pandemic situation of Covid-19, learning can now be realised online and knowledge can be transferred virtually using multiple media. Online learning is the best solution during this crisis. Online learning is a learning environment that takes place over the Internet. It is often referred to as e-learning. An online educator compensates the lack of physical presence in the virtual classroom by creating a supportive environment where all 
students feel comfortable to participate in online class (Joshua). It plays a significant role in transforming our lives to digital world by providing flexible places, class timings and quality contents. It provides a way to the development of humanity at the time physical isolation due to pandemic. Online learning is beneficial because it is instantly accessible and offers flexible scheduling. In this system, learners use Internet technology to communicate virtually with their teachers and fellow learners through Email, WhatsApp, Videoconferencing, Instant messaging or using other tools. However Videoconferencing may be effectively used in online learning to enhance group collaboration with sense of community between learners which may replace face to face class room learning to some extent. In the past, students of rural areas were missing many of the opportunities that their urban and suburban peers had taken for granted. Connecting these rural students for online learning via video conferencing can dramatically improve the quality of their learning experience. This enables the rural/disadvantaged learners to both attend school/college from home and gives them access to the experts. Videoconferencing is a synchronous model for interactive voice, video and data transfer between two or more groups/people (Wiesemas \& Wang, 2010). Videoconferencing is just one of the technological systems that can be used in online learning. The value of online learning is being recognized by more organizations, since it is a cost effective way to deliver a large number of people. It can produce significant results by not only decreasing costs, but also by improving performance. Online Learning is encouraged due to following reasons during lockdown period for Covid-19.

$>\quad$ One can acquire knowledge staying at home and can maintain social distancing.

$>$ Outbreak of Covid-19can be minimised due to social distancing

$>$ It offers highly effective learning environments.

$>$ It offers complementary interactive support that allows students to study 24/7 and work at their own pace.

$>$ It offers flexible scheduling.

$>$ It is available in any location, with an internet connection and students can attend using their devices (mobile, computers, tablets, etc.).

$>$ Deals with real-time student monitoring as well as reporting.

$>$ Improves the image of institution by offering technological solutions that solve real problems

\section{Objectives}

The objectives of the study are to:

- Study the measures taken by Government of India to support online learning process during the lockdown period for Covid-19.

- Enlighten various online tools/platforms adopted by educational institutions during the pandemic Covid-19.

- Highlight some merits and demerits of Online Learning and put suggestions for improvement.

- Enlist the views of learners and educators on online learning system during lockdown.

Methodology

Some journals and e-contents relating to online learning system are studied to find out the problems associated with online learning system especially during pandemics. 


\section{International ournal of MultidisciplinaryEducational Research ISSN:2277-7881; IMPACTFACTOR :6.514(2020); IC VAWE:5.16; ISI VAWE:2.286 \\ Peer Reviewed:VOLUME:9, ISSUE:5(8), MAY:2020}

Measures taken by Govt. of India to support online learning process during the lockdown period for Covid-19 are collected from website. Author has undertaken some online counselling classes and conducted online induction meetings with fresh January 2020 learners of different Learner Support centres (LSCs) under Indira Gandhi National Open University(IGNOU) Regional centre, Bhubaneswar during the lockdown period of India. The perceptions/views of learners and educators of LSCs under IGNOU Regional centre, Bhubaneswar are collected while conducting online counselling classes and online induction meetings using videoconferencing software ZOOM/Google Meet. The collected data are analyzed to study merits and demerits of Online Learning system during lockdown and proposed better methods to make it effective for the learners.

\section{Initiatives of India for online learning during lockdown}

Since countries all over the world have gone into lockdowns due to Covid-19, educational institutes have been no exception. During the Covid-19 outbreak in the entire nation, the country is facing major crisis in many sectors but the worst hit sector is the education sector, as most of the exams have been cancelled during the final assessments. Students and teachers are struggling to have access to uninterrupted and seamless quality of internet connection. At the same time, the country should not compromise student's much desired academic progress. Hence, educational institutions should adopt smart solutions to overcome the endemic crisis by adopting the online mode of education. Many State Governments of India are also exploring online learning platform for accessing online educational resources, during the ongoing lockdown. They are looking to design ways to help students continue with their learning during the nationwide lockdown due to Covid-19. The aim is to effectively continue with the academic cycles of the students and not let the lockdown affect their learning. They are planning for students to provide audio and video based content along with selfassessment exercises. Special doubt- clearing sessions on important topics may be held for students. People of India need to continue with coordinated and collective efforts to fight Covid-19 and also make productive use of their time during the current situation by adopting Information and Communication Technology (ICT) for teaching learning process and contribute towards the intellectual wealth of the nation. Online classes have been promoted across the different universities by the University Grants Commission (UGC) during the lockdown phase in order to make sure that the students do not miss out on the classes during the time. While speaking to the media on 13.04.2020 (DD news), UGC Chairman declared that the UGC has constituted two committees to promote online learning during Covid-19 lockdown. One of the committees has been formed for the examinations and academic calendar, while the second committee will work on students, teachers and the education system. Based on the suggestions of the committee and in consultation with the Ministry of Human Resource Development (MHRD) the guidelines for the universities may be issued by the UGC very soon. UGC has advised all higher educational institutes in the nonfiction dated 11th April 2020 to take preventive and precautionary measures for maintaining social distancing, staying in the confines homes/hostels and utilise the time productively by engaging in on-line learning during the lockdown period for Covid-19. The resources, which are in the form of digital platforms, can be accessed by the teachers, students and researchers in 
Universities and Colleges for expansion of their knowledge. To ensure that there is no break in the education and students get full-access to classes, like before, MHRD advises students to carry on with their studies using the online learning platforms. The online learning platforms help the students not only get full access to the study material but also allow them to engage in online classes and interact with the teachers like the physical classroom setting. Following is the list of some of the digital initiatives of MHRD \& UGC along with their access links for school students as well as UG and PG level education:

1. SWAYAM online courses: provides access to best teaching learning resources which were earlier delivered on the SWAYAM Platform may be now viewed by any learner free of cost without any registration. Students/learners who registered on SWAYAM (swayam.gov.in) in the January 2020 semester can continue their learning as usual. Link-https://storage.googleapis.com/uniquecourses/online.html

2. UG/PG MOOCs: hosts learning material of the SWAYAM UG and PG (NonTechnology) archived courses.

Link- https://ugcmoocs.inflibnet.ac.in/ugcmoocs/moocs_courses.php.

3. e-PG Pathshala: hosts high quality, curriculum-based, interactive e-content containing 23,000 modules (e-text and video) in 70 Post Graduate disciplines of social sciences, arts, fine arts and humanities, natural \& mathematical sciences.

Link- epgp.inflibnet.ac.in

4. e-Content courseware in UG subjects: e-content courseware in 87 Undergraduate courses with about 24,110 e-content modules is available on the CEC website at http://cec.nic.in/.

5. SWAYAMPRABHA: is a group of $32 \mathrm{DTH}$ channels providing high quality educational curriculum based course contents covering diverse disciplines such as arts, science, commerce, performing arts, social sciences and humanities subjects, engineering, technology, law, medicine, agriculture etc to all teachers, students and citizens across the country interested in lifelong learning. These channels are free to air and can also be accessed through your cable operator. The telecasted videos/lectures are also as archived videos on the Swayamprabha portal.

Link- https://www.swayamprabha.gov.in/

6. CEC-UGC YouTube channel: provides access to unlimited educational curriculum based lectures absolutely free. Linkhttp://www.youtube.com/user/cecedusat

7. National Digital Library: is a digital repository of a vast amount of academic content in different formats and provides interface support for leading Indian languages for all academic levels including researchers and life-long learners, all disciplines, all popular form of access devices and differently-abled learners.

Link- https://ndl.iitkgp.ac.in/

8. Shodhganga: is a digital repository platform of 2,60,000 Indian Electronic Theses and Dissertations for research students to deposit their Ph.D. theses and make it available to the entire scholarly community in open access.

Link- https://shodhganaa.inflibnet.ac.in

9. e-Shodh Sindhu: provides current as well as archival access to more than $\mathbf{1 5 , 0 0 0}$ core and peer-reviewed journals and a number of bibliographic, citation and factual 
databases in different disciplines from a large number of publishers and aggregators to its member institutions including centrally-funded technical institutions, universities and colleges that are covered under I2(B) and 2(f) Sections of the UGC Act.

Link- https://ess.inflibnet.ac.in/

10. Vidwan: is a database of experts which provides information about experts to peers, prospective collaborators, funding agencies policy makers and research scholar in the country. "It is hoped, that these ICT initiatives, which cover a broad range of subjects and courses and have been prepared by experts, will provide an excellent learning experience to all. Link- https:/vidwan.inflibnet.ac.in/

\section{Emerging approaches of Govt. of India for online learning}

In a press release put out by the MHRD on March 21, 2020, the Union HRD Minister shared various free digital Online Learning platforms for students to continue their learning during Covid-19 based school closures. The World Bank is also sorting emerging approaches undertaken by different countries, and storing all related information which may be useful to others. The emerging approaches of India shared by World Bank are as listed below.

- The DIKSHA portal contains online learning content for students, teachers, and parents aligned to the curriculum, including video lessons, worksheets, textbooks and assessments. Under the guidance of its national board of education (CBSE) and NCERT, the content has been created by more than 250 teachers who teach in multiple languages. QR codes in textbooks encourage students to go beyond the book. The app is available to use offline.

- e-Pathshala is an online learning app by NCERT for classes 1 to 12 in multiple languages. The app houses books, videos, audio, etc. aimed at students, educators and parents in multiple languages including Hindi, Urdu, and English.

- The National Repository of Open Educational Resources (NROER) portal provides a host of resources for students and teachers in multiple languages including books, interactive modules and videos including a host of STEM-based games. Content is mapped to the curriculum for classes $1-12$, including aligned resources for teachers.

- Swayam hosts 1900 complete courses, including teaching videos, weekly assignments, exams and credit transfers, aimed both at school (class 9 to 12) and higher education (undergraduate and postgraduate) levels. Subjects are aligned to the curriculum and include engineering, humanities, social sciences, law and management courses including robotics.

- Swayam Prabha is a group of 32 Direct To Home (DTH) channels devoted to telecasting of educational programs round the clock and accessible all across the country. The channels air courses for school education (class 9-12), higher education (undergraduate, postgraduate) as well as for out-of-school children, vocational education and teacher training. Subjects include arts, science, commerce, performing arts, social sciences, humanities, engineering, technology, law, medicine, and agriculture. Schedules for the television broadcast as well as archived programs are available on the website. 


\section{Some free external repositories of distance learning solutions}

UNESCO has suggested the list of educational applications, platforms and resources below with an aim to help parents, teachers, schools and school administrators facilitate student learning and provide social care and interaction during closure of educational institutions. Most of the solutions are free with multiple language option. They are categorized based on distance learning needs, but most of them offer functionalities across multiple categories.

- Brookings - A catalogue of nearly 3,000 learning innovations. Not all of them are distance learning solutions, but many of them offer digital education content.

- Common Sense Education - Tips and tools to support school closures and transitions to online and at-home learning.

- Commonweatlh of Learning - List of resources for policymakers, school and college administrators, teachers, parents and learners that will assist with student learning during the closure of educational institutions.

- Education Nation - Nordic countries have opened up their learning solutions for the world for free, supporting teachers and learners during the school closures.

- EdSurge - Community-driven list of edtech products, including many distance learning resources for students, teachers and schools, covering primary to postsecondary education levels.

- Global Business Coalition for Education - List of online learning platforms, information sharing platform and communication platforms.

- Keep Learning Going - Extensive collection free tools, strategies, tips and best practices for teaching online from a coalition of USA-based education organizations. Includes descriptions of over $600+$ digital learning solutions.

- UNHCR - An extensive list of over 600 distance learning solutions from the United Nations agency for refugees.

Free online platforms that support live-video communication

There are many live-video communication platforms are available in web, but some of the free online platforms are as listed below which can be used by learners of all categories:

- Zoom - Cloud platform for video and audio conferencing, collaboration, chat and webinars.

- Google Meet - Video calls integrated with other Google's G-Suite tools. Video meeting recordings, Screen sharing, Join calls using Google Calendar

- Skype - Video and audio calls with talk, chat and collaboration features.

- Facebook Live- is a great fit for businesses, influencers, or individuals who are looking to broadcast demos, videos, or showcase their company culture while streaming live, followers on Facebook can comment and chat live, schedule videos ahead of time to gain excitement.

- YouTube Live-is a platform for demonstrating a product with live interaction, hosting an educational session to teach audience with screen sharing or using a whiteboard, having features with Location tags and advanced scheduling. 
- UberConference- Unlimited Video and audio calls with talk, chat and collaboration features

- FreeConference is ideal for smaller teams or meetings, feature include Screen sharing, Document sharing, Text sharing etc.

- Dingtalk - Communication platform that supports video conferencing, task and calendar management, attendance tracking and instant messaging.

- Lark - Collaboration suite of interconnected tools, including chat, calendar, creation and cloud storage, in Japanese, Korean, Italian and English.

- Teams - Chat, meet, call and collaboration features integrated with Microsoft Office software.

- TrueConf Online-HD video with Collaboration tools (screen sharing, remote desktop control, recorded calls, file transfer and shared virtual whiteboard).

- Slack Video Calls- is good for teams looking for a supplementary video calling solution for small teams, features include individual calls and messenger services.

- Lifesize Go- No restrictions on meeting length, preferred for small group conversations.

\section{Merits of online learning during lockdown}

- Online Learning encourages more productive use of time which keep individuals safe from pandemic situation like spread of Covid-19.

- It has greater access to experts/specialists (nationally and internationally) and learners can access $24 / 7$ at their own pace and time. It allows geographical reach even to rural or remote locations.

- It is a cost-effective technology which is quite affordable and enhances communication between educators and students. One educator can teach various virtual classes simultaneously which reduces travelling to various places. It can accommodate more learners at a particular time.

- Online class/conference session can be saved in website for future reference e.g. class notes can be saved and distributed via network for references by students. The digital recordings of the classes/meetings can be uploaded in website to review later.

- In order to conduct exams, institutions may consider using online examination software which may help for conducting online examinations. This will prevent institutions in facing delays in its annual academic calendar for lockdown.

- Very useful to some emergency service personnel like police, doctor and nurses etc. who are unable to spare a specific time to learn during lockdown can use the online recordings and pursue their education.

- Useful to women and physically handicapped learners who can learn at home.

\section{Demerits of online learning during lockdown}

- Not all children have the necessary knowledge, skills and resources to keep themselves safe online. Spending more time on virtual platforms can leave children vulnerable to online sexual exploitation.

- Learners from low-income families and disadvantaged groups are the more likely to suffer during online learning as they may not afford high-speed internet connection 
and required technical gadgets. It widens gap between privileged and unprivileged learners.

- It may lead to laziness with some students being at their home and may lack self discipline.

- The atmosphere of a face-to-face meeting is lost. Interpersonal relationship between students and teachers or between students may hamper.

- The security of personal data may be compromise as one can hack the digital devices without latest software updates and antivirus programs.

\section{Perception of learners on online learning during lockdown}

- Felt happy due to utilisation of time in attending online classes during the lockdown period. Initially, faced some difficulty in joining online classes but got acquainted later on.

- Feeling lonely and unable to share feelings with peers. Observed poor audio/video quality in some locality due to poor network.

- Some emergency service personnel like police, doctor and nurses etc. who do not get much time to interact in online classes make use the recordings of online classes to pursue their study during the lockdown have shown their satisfaction.

- Requesting to facilitate practical based classes through virtual laboratories.

- Requesting to upload all recordings of online classes in website for further reference of the learners as well as educators as per their requirements. Using the online recordings of classes/meetings learners are able to revise the concepts again and again to clarify their doubts for better understanding the subject.

- Online teaching should be delivered in local/regional languages so that everybody could interact comfortably.

- Improved required technical skills due to Online Learning programme and requesting for provision of online examination during lockdown period.

- Online learning is felt to be less effective, less systematic and less organized than the conventional system of education. So, face to face classes for the same courses may conducted again after the end of lockdown

- Very effective for women and physically handicapped learners who can learn at home.

- Do not receive prior information on online class or induction meeting schedule and cannot attend.

- Feeling unhappy for not having required technically knowledge to join online learning and unable to afford required technical gadgets with high speed internet for online learning.

\section{Perception of educators for online learning during lockdown}

- Felt happy due to utilisation of time in conducting online classes during the lockdown period. Initially, faced some difficulty in conducting online classes but got acquainted later on and conducted the classes smoothly. 
- Ensuring prior information on online class or induction meeting schedule would help the educators in better preparation of subject matter for efficient delivery of online classes/induction meetings.

- All recordings of online classes should be uploaded in website for further reference of the learners as well as educators as per their requirements.

- As the lockdown was declared unexpectedly, most of the institutions could not decide the rates of remuneration of educators for online classes. So, the financial issue relating to remuneration and expenditure towards internet data package should be clarified by the host institutions.

- As the learners are present at scattered places during online classes, it becomes difficult for an educator to monitor their activities in real time. It is also difficult to draw their attention towards the subject matter during the online classes.

- Very poor attendance and less interaction of learners are observed in online classes. Sometimes poor video and audio quality obstruct in smooth functioning of online classes.

\section{Suggestions}

Some useful steps for smooth functioning of Online Learning are as suggested below:

1. Online platforms with enhanced safety and safeguarding measures, especially for virtual learning tools should be ensured. The devices must have the latest software updates and antivirus programs otherwise the security of personal data may be compromised as one can hack the digital devices.

2. High speed internet connectivity should be ensured in order to improve smooth access for all including learners of disadvantaged groups and low-income families.

3. All should follow the new guidelines released by UNICEF and partners to keep kids safe during online classes.

4. Schools should monitor good online behaviours of children while conducting online classes.

5. Parents should ensure that children's devices have the latest software updates and antivirus programs. They should work with children to establish rules for how, when, and where the internet can be used. They should also speak to their children on how and with whom they are communicating online.

6. Social networking platforms should enhance online platforms with more safety measures, especially while using virtual learning tools.

7. Government should take necessary steps to train all stakeholders of education on online learning platform to tackle such crisis of lockdown during any pandemics. Government should create awareness on online education with safety measures for children and take measures to create awareness on cyber security.

8. Online learning is not affordable for all including the poor and disadvantaged groups of the society. So necessary steps should be taken by Government/educational institutions to minimise this gap between privileged and unprivileged learners.

9. Learners and educators must be familiar with Web-based interactions such as email, discussion boards and chat rooms before joining online classes. 


\section{International ournal of MultidisciplinaryEducational Research ISSN:2277-7881; IMPACTFACTOR :6.514(2020); IC VAWE:5.16; ISI VAWE:2.286 \\ Peer Reviewed:VOLUME:9, ISSUE:5(8), MAY:2020}

10. Government/educational institutions should adopt the policy to provide free internet and free digital gadgets to all learners in order to encourage online learning as a result of which people would get engaged themselves during lockdown and remain safe from pandemics.

\section{Conclusions}

Online Learning is the most common method of distance learning today. During the lockdown period for Covid-19, online learning is the best platform to keep learners/educators engaged and safe by maintaining social distancing. Govt. of India has initiated different online learning platforms to continue educational activities during lockdown period which are also been recognised by UNESCO and World Bank. Online Learning method utilises various applications of the internet to distribute classroom materials and help learners and educators interact with one another. Using the various technologies available for Online Learning, educators can provide a more interactive distance learning experience by delivering real-time, synchronous video conferencing. Online learning is considered as future learning process and this platform has a potential of overall change in pedagogy of teaching learning in the modern world. However, necessary steps must be taken to train all stakeholders of education on online learning platform. Government/educational institutions should adopt the policy to provide free internet and free digital gadgets to all learners in order to encourage online learning as a result of which people would get engaged during lockdown and remain safe from pandemics. Online Learning is the best method of learning at this time of lockdown due to the outbreak of Covid-19 and further in-depth statistical study may be undertaken on impact of online learning during lockdown period.

\section{References}

1. DD news. UGC forms committee to encourage online learning amid lockdown. Retrieved on April 16, 2020 from http://ddnews.gov.in/national/ugc-formscommittee-encourage-online-learning-amid-lockdown

2. Google search. Best Free Video Conferencing Tools. Retrieved on April 15, 2020 from https://www.owllabs.com/blog/video-conferencing-tools

3. Joshua Stern. Introduction to Online Teaching and Learning. Retrieved on April 17, 2020 from http://www.wlac.edu/online/documents/otl.pdf

4. UGC notice. An Appeal for Inviting ideas/ suggestions for "Bharat Padhe Online campaign”. Retrieved on April 16, 2020 from https://www.ugc.ac.in.

5. UGC notice. LET COVID 19 not stop you from learning-ICT initiatives of MHRD \& UGC. Retrieved on April 16, 2020 from https://www.ugc.ac.in.

6. UNESCO. COVID-19 Educational Disruption and Response. Retrieved on April 14, 2020 from https://en.unesco.org/covid19/educationresponse

7. UNESCO. Distance learning solutions. Retrieved on April 14, 2020 from https://en.unesco.org/covid19/educationresponse

8. UNICEF. Children at increased risk of harm online during global COVID-19 pandemic. Retrieved on April 16, 2020 from https://www.unicef.org/turkey/en/press-releases/children-increased-risk-harmonline-during-global-covid-19-pandemic 


\section{International ournal of Multidisciplinary Educational Research ISSN:2277-7881; IMPACTFACTOR :6.514(2020); IC VAWE:5.16; ISI VAWE:2.286 \\ Peer Reviewed:VOLUME:9, ISSUE:5(8), MAY:2020}

9. Wiesemes, R. \& Wang, R.(2010). Video conferencing for opening classroom doors in initial teacher education: sociocultural processes of mimicking and improvisation. International Journal of Media, Technology and Lifelong Learning, 6(1): 1-15.

10. World Bank. How countries are using edtech to support access to remote learning during the COVID-19 pandemic. Retrieved on April 16, 2020 from https://www.worldbank.org/en/topic/edutech/brief/how-countries-are-using-edtechto-support-remote-learning-during-the-covid-19-pandemic 